\title{
Reference roving at Boston College
}

By Adeane Bregman and Barbara Mento

\section{Moving away from the reference desk to reduce stress}

$\mathbf{T}$ he explosion of electronic resources has forced our library and many others to review traditional methods of providing reference services. Boston College (BC) created the "reference rover" to address patrons' needs brought about by this explosion. The reference rover is a staff member who circulates among the various electronic resources to offer assistance at the point of use. Patrons appreciate the individualized instruction available when they need it and are left with a sense of accomplishment. Helping patrons at the point of use gives librarians a means of keeping up to date on the new resources and also provides an idea of how patrons deal with the technology. At the O'Neill Library we found reference roving to be not only an effective way to address user needs, but also a way to manage the stressful impact of electronic information resources on the delivery of reference services.

\section{Background}

The idea of librarians asking patrons if they needed help as opposed to patrons asking librarians came as a result of the Reference Department's discussions on the future of reference service at $\mathrm{BC}$. The department held a day-long retreat to plan for the various changes it faced at that time which included:

- introducing a new online library catalog, changing from a GEAC to a NOTIS system;

- upgrading of the MultiPlatter system from four stand-alone workstations to a ten-station LAN (local area network) with access to six different $\mathrm{CD}$-ROM databases;
- installing two UMI databases ( $A B I$ Inform and Dissertation Abstracts) at a standalone workstation near four Infotrac workstations and next to the Oxford English Dictionary workstation;

- relocating the workstation used for Dow Jones News Retrieval and BRS After Dark from the reference desk to a location some 10 feet away;

- upgrading the OCLC terminal.

The O'Neill Library supports over 50 public workstations in the Electronic Information Area. The resources are accessible to a student body of approximately 14,000 and a faculty of over 700. In addition, as a member of the Boston Library Consortium our resources are shared by 11 area libraries, many area businesses, and the community at large. The impending changes made us understandably concerned about the impact of the proliferation of electronic resources on both an already stressed staff and our patrons who had to deal with these changes too.

We anticipated that our patrons would need the most help in differentiating between the various electronic information systems and learning the skills of searching each one. We had already perceived patrons' confusion over which system to use and which commands and features, such as the truncation symbol, were appropriate for each.

Traditionally we had staffed the reference desk 92 hours a week and waited for patrons to request our assistance. Some inquiries were answered at the desk, but questions involving search strategies and computer skills required that the member of the reference staff leave the desk to help the patron at the workstation, sometimes for extended periods of time. 


\section{Reference roving}

In light of all the proposed changes and the increase in the number and variety of workstations, the Reference Department discussed the impact of spending more time away from the reference desk. After brainstorming for possible solutions to this problem, we decided that Iibrarians and staff should "rove" around the area where the electronic resources were located to assist patrons as they needed help and instruction.

It was hoped that reference roving would reduce stress for both staff at the reference desk and for patrons at workstations by providing immediate assistance and instruction.

Reference roving began in the fall of 1989 after orientation sessions for new students and introductory sessions to our new NOTIS online catalog, QUEST, were completed. The new roving service consisted of 20 onehour shifts (Monday through Friday from 11:00 a.m. to 3:00 p.m.), added to our regular schedule. Librarians and staff from circulation, cataloging, and the special campus libraries asked to be included in the reference roving schedule. Outside staff viewed roving as an opportunity to increase their knowledge of our electronic resources, while reference staff benefited from the additional help.

To determine the impact on patrons and to evaluate the new service, two surveys were designed. One survey was developed to determine what type of assistance patrons required most often from our rovers and the other to establish a profile of our users.

\section{First survey summary}

The first was a statistical survey designed to record the number of times a user needed technical assistance (i.e., use of command language and function keys, machine problems) and conceptual assistance (i.e., search strategies, determining the appropriate system, explanation of a thesaurus). Statistics were collected by rovers over an eight-week period and provided data on approximately 1,093 interactions. The following areas of user assistance are listed in order of frequency:
- search strategies;

- mechanical problems (machine freezes, inadequate supply of paper and ink, etc.);

- search mechanics (appropriate commands, how to print, etc.);

- overall introduction to the system;

- screen interpretations;

- appropriate resource choice (patron using the wrong system).

We found that about three-fourths of the rover interactions lasted less than five minutes. Guiding our users to the right system or strategy at the beginning of the search process saved time because reference staff aren't running between the reference desk and the workstations. As a result the patron' $s$ approach is more efficient from the outset.

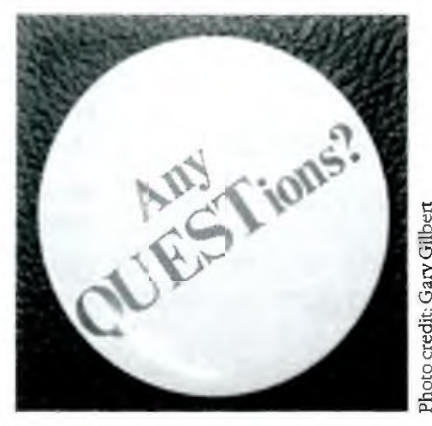

Reference rovers sport these buttons while roving. Because ir visibility has increased, patrons now recognize and stop them even when they aren't wearing their buttons.
Second survey summary The goal of the second survey was to provide a profile of our users. To get a broad sampling, 70 patrons were randomly interviewed during various rover shifts. Our profile indicated that $90 \%$ of our electronic information users had some computer experience; $71 \%$ had searched the system they were using at least once before; and $64 \%$ had received some sort of assistance. Of those users who had received assistance, 98\% said they found the assistance useful. Overall, $90 \%$ of the users said they found the information they needed. This high success rate has led to greater user satisfaction and reduced demands on the staff.

As a result of these surveys, the roving reference service was expanded two hours each day, extending coverage from 10:00 a.m. to 4:00 p.m. and steps were taken to address the areas where patrons needed the most assistance. The department scheduled additional tours and demonstrations at the beginning of each semester to explain the various systems. Signs listing the available databases were placed above each workstation. Selected keys on the workstation keyboards were either disabled or reprogrammed to resolve some mechanical problems. Student library assistants were asked to monitor the printers on a regular basis and to check for adequate paper and ink supplies. 


\section{First New Edition in Eight Years!}

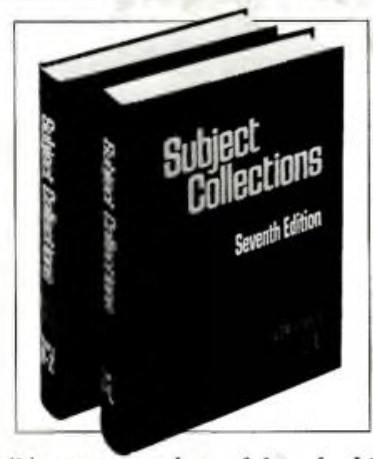

\section{0,000 Collections... 23,000 Subject Areas...}

\section{All in One!}

"An enormously useful work which few libraries can afford to pass up."

- Library Journal*

"A high priorily acquisition for all types of libraries." - American Reference Books Annual*

"Its supreme usefulness to collectors, dealers, and librarians is so enormous..."

-American Book Collector*

Lee Ash's

\section{Subject Collections ${ }^{\text {Tw }}$ 7th Edition}

Compiled and Edited by Lee Ash and William G. Miller

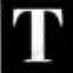

his cornerstone resource gives you access to thousands of speeial collections, covering just about every conceivable subject area. Extensively revised and expanded, the 7 th Edition features:

- 30,000 specialized collections in the U.S. and Canada - 6,000 new to this edition

- 8,000 academic, public, and special libraries, as well as federal and state special collections

- 2,000 collections in museums for greater access to even more subjects

- 1,000 new subjects - 23,000 LC headings in all — including Apparel...Banks and Banking...

Beach Protection...Music, Theater...Soil Conservation... and more

- Plus, cross references to quickly pinpoint the information you need.

January $1993 \cdot 0-8352-3141-0 \bullet$ c. 2,500 pp. $\bullet \$ 275.00$ Available on Standing Order.
And for Definitive Information on Libraries, Librarians, Services, and More...

American Library Directory ${ }^{n}$ 1992-93, 45th Edition

Cited in Sheehy's Guide to Reference Books

"...one of the most valuable resources for information on libraries."

- American Reference Books Annual

Ameriean Library Directory 1992-93 keeps you in touch with the latest, most authoritative information availuble on more than 35,000 public, academic, special, and government libraries, and library-related organizations in the U.S, and Canada.

July 1992•0-8352-3157-7•2-vol. set $\bullet 2,477$ pp. $\$ 215.00$. Available on Standing Order.

For more information, call

\section{1-800-521-8110.}

Dial " 1 " for Customer Service and ask for Operator FJP.

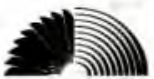

R.R.BOWKER

A Reed Reference Publishing Company. 121 Chanlon Road, New Providence, NJ 07974

"From revienes ef the 6th Edition.

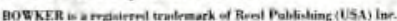


Since the initiation of reference roving, three new dial-in services (Lexis/Nexis/Medis, Dialog/ Classmate, and Univnet), a Latin American wire service, and two CD-ROM databases (Million Dollar Directory and National Newspaper Index on Infotrac) have been added. Three Wilson databases (Humanities, Social Sciences, and General Science Indexes) were mounted on our NOTIS system and the UMI databases were moved onto our MultiPlatter network, along with PAIS and GPO. Having the roving service already in place, we were able to effectively introduce the new systems to our patrons.

\section{Conclusion}

A poll of the reference staff a year later indicates that our staff unanimously think reference roving is worthwhile and should be continued. It makes staff more accessible and allows time for in-depth help on an individual basis. Roving provides the opportunity for a pro-active approach and a first-hand view of how patrons use electronic resources. It also helps relieve the stress felt at the reference desk by allowing referrals to the reference rovers.

Several recent articles, including Charles A. Bunge's "CD-ROM Stress" (Library Journal, April 15, 1991), emphasized that this proliferation of electronic resources has led to the rise of technostress in reference departments. Reference roving at Boston College's O'Neill Library has proved to be a successful approach for dealing with these problems and meeting our patrons' needs.
(Academic reference cont. from page 632)

idea of how fast the service may or may not be and how appropriate to present need. (We have been checking five times a day, seven days a week; but we had not communicated this to our users and a few have expressed disappointment that they did not get speedier replies. They may have imagined some ongoing constant monitoring.)

6) Pick up the messages regularly and monitor that responses have been sent. In our case the office manager assumes this task Monday through Friday. She then gives the questions to the librarian or staff member on duty at the Reference Desk. Another model might be to rotate the responsibility on a weekly basis to individual staff members. Whatever the model, it is important that the expertise of the staff be utilized when appropriate. Any question we receive on cinema goes automatically to our resident expert. One of the benefits of email is that it allows you to take advantage of such expertise. It frees both librarian and patron from the lottery they each face in handling reference transactions over the telephone or in person-when an answer to the question is most often attempted immediately by the person on duty, whatever subject or language expertise they may or may not possess.

7) Cite the source your "fact" comes from. This need not be in correct and complete bibliographic form, unless that is requested. That associate instructor who uses us to double check facts his students use in their papers has reminded us again that one woman's fact is another's mistake. Unless you plan to check the fact in six different sources (finding three different answers), pick a reputable source and say what it is. This principle is hardly unique to reference work in an electronic setting. That it's worth mentioning here probably reflects the fact that librarians and staff accustomed to the generally unmonitored, oral, one-on-one style of most reference work may respond differently to written communications which may be viewed (and reviewed) by their colleagues. It is a good reminder of the form and substance of the answers we give to all questions.

8) This service will likely stimulate demand for other library services such as document delivery, databases beyond our own line catalogs, and expert systems designed within specific ranges of inquiry. The responses we received about the delivery service and additional databases over the network were not motivated only by local events but by a vision of the total array of services desired from the scholar's own workstation.

Even in the richest, most intelligent online environment, however, there is probably a useful niche for a "reference" option. Such an option requires the user to know only what she wants to know and to answer no questions about her question before she can ask it! It is a service users appreciate.

\section{Note}

'Described in this joumal by Miriam Bonham, "Library services through electronic mail," CERL News 48:9 (October 1987): 537-38. 